\title{
The antagonistic effect of neostigmine on rocuronium-, clindamycin-, or both-induced neuromuscular blocking in the rat phrenic nerve-hemidiaphragm
}

\author{
Seung Soo Kim, Soo-Il Lee, Chan Jong Chung, and Seung-Cheol Lee \\ Department of Anesthesiology and Pain Medicine, Dong-A University College of Medicine, Busan, Korea
}

Background: Neostigmine augments clindamycin-induced neuromuscular block and antagonizes rocuroniuminduced neuromuscular block; however, it remains unclear whether neostigmine enhances the neuromuscular blocking (NMB) that is caused by combinations of rocuronium and clindamycin. The intent of this study was to determine whether neostigmine potentiates the muscle relaxation that is induced by combinations of rocuronium and clindamycin and to estimate whether both clindamycin and rocuronium have synergistic actions on NMB.

Methods: Forty-one left phrenic nerve-hemidiaphragms (from male Sprague-Dawley rats, 150-250 g) were mounted in Krebs solution. Three consecutive single twitches (ST, $0.1 \mathrm{~Hz}$ ) and one tetanic tension (50 Hz for $1.9 \mathrm{~s}$ ) were obtained for each increase in concentration of rocuronium or clindamycin. The concentrations of rocuronium were cumulatively increased until an $80 \%$ to $90 \%$ reduction in ST was attained in the Krebs solutions pre-treated with 0 $(\mathrm{n}=5), 0.1(\mathrm{n}=1), 0.25(\mathrm{n}=1), 0.5(\mathrm{n}=4)$, or $1.0(\mathrm{n}=1) \mathrm{mM}$ clindamycin or with $0(\mathrm{n}=4), 0.1(\mathrm{n}=1), 0.5(\mathrm{n}=5), 1.0$ $(\mathrm{n}=5)$, or $2.0(\mathrm{n}=4) \mathrm{mM}$ clindamycin in combination with $250 \mathrm{nM}$ neostigmine, and so were the concentrations of clindamycin in the Krebs solutions pre-treated with $0(\mathrm{n}=6)$ or $250 \mathrm{nM}(\mathrm{n}=6)$ neostigmine.

Results: Clindamycin increased the potency of rocuronium for ST and tetanic fade, irrespective of the presence of neostigmine. Neostigmine shifted the concentration-response curve of rocuronium to the right in the presence or absence of clindamycin. The interaction between rocuronium and clindamycin was synergistic when clindamycin concentrations were in excess of $0.5 \mathrm{mM}$, irrespective of the presence of neostigmine.

Conclusions: Neostigmine may partially antagonize the neuromuscular block that is induced by a combination of clindamycin and rocuronium. Clinicians are advised to be aware that clindamycin synergistically increases the degree of rocuronium-induced neuromuscular block, even when neostigmine is present. (Korean J Anesthesiol 2011; 61:320-326)

Key Words: Clindamycin, Neostigmine, Neuromuscular block, Reversal, Rocuronium, Synergy.

Received: May 16, 2011. Accepted: May 20, 2011.

Corresponding author: Soo-Il Lee, M.D., Department of Anesthesiology and Pain Medicine, Dong-A University Hospital, 1, Dongdaesin-dong 3ga, Seo-gu, Busan 602-715, Korea. Tel: 82-51-240-5390, Fax: 82-51-247-7819, E-mail: silee@dau.ac.kr

(c) This is an open-access article distributed under the terms of the Creative Commons Attribution Non-Commercial License (http:// creativecommons.org/licenses/by-nc/3.0/), which permits unrestricted non-commercial use, distribution, and reproduction in any medium, provided the original work is properly cited. 


\section{Introduction}

Because many antibiotics are administered 60 minutes before surgical incision to prevent surgical site infection [1], perioperative antimicrobials are typically administered before anaesthesia. Anaesthesiologists are often responsible for the administration of antibiotics in the preoperative and intraoperative periods; however, they may be unfamiliar that the administration of antibiotics is associated with the potentiation of neuromuscular blocking (NMB) agents [2].

Most antibiotics have been reported to cause neuromuscular block in the absence of NMB drugs [3]. Therefore, the use of antibiotics can prolong the duration of mechanical ventilation $[4,5]$. Because some antibiotics can not only enhance NMB drug-induced muscle relaxation, but also complicate the antagonism of the neuromuscular block, control of ventilation is necessary until there is spontaneous recovery of the neuromuscular block [6].

Clindamycin is a 7-chloro-7-deoxy derivative of lincomycin. Clindamycin has typically been used to treat infections that are caused by anaerobic and aerobic bacteria other than enterococci [1]. In addition to having antibacterial effects, clindamycin produces an open ion channel block on the end-plate $[7,8]$ and decreases acetylcholine release at the motor nerve terminal [9], thus, prolonging or enhancing neuromuscular block that is caused by nondepolarizing NMB drugs [10-14].

While neostigmine antagonizes nondepolarizing NMB druginduced neuromuscular block, it augments or incompletely antagonizes the NMB that is induced by combinations of some antibiotics and NMB drugs $[11,15,16]$. It has been demonstrated that neostigmine augments clindamycin-induced neuromuscular block [17]; however, it remains unclear whether neostigmine enhances the neuromuscular block that is caused by a combination of rocuronium and clindamycin.

Becker and Miller [11] have shown that the combination of clindamycin and d-tubocurarine or pancuronium synergistically depresses twitch tension. However, there are no reports investigating the effect of clindamycin on rocuronium-induced muscle relaxation or the interaction between clindamycin and rocuronium on neuromuscular block. The Loewe additivity model [18] has been established as the universal reference model for classifying drug interactions [19]. When the interaction index as per the Berenbaum method [20] is equal to, less than or greater than unity, the combination dose is labelled as additive, synergistic or antagonistic, respectively.

The intent of this study was to determine whether neostigmine potentiates the muscle relaxation that is induced by combinations of rocuronium and clindamycin and to estimate whether both clindamycin and rocuronium have synergistic actions on neuromuscular block.

\section{Materials and Methods}

The Institutional Animal Care and Use Committee approved the experimental protocol. All experimental courses followed the Guide for the Care and Use of Laboratory Animals provided by the National Academy of Sciences. Forty-one male SpragueDawley rats (150-250 g in weight) were anesthetized by a perivertebral injection of propofol (50 mg/ $\mathrm{kg}$ ) at the lumbar level and then killed. The phrenic nerve and diaphragm were excised together and the left diaphragm with the middle diaphragmatic ligament was separated from the rest of the diaphragm. Left phrenic nerve-hemidiaphragm preparations were mounted in a $20-\mathrm{ml}$ organ bath that had been filled with Krebs solution (118 mM NaCl, $5 \mathrm{mM} \mathrm{KCl,} 2.5 \mathrm{mM} \mathrm{CaCl}_{2}, 30 \mathrm{mM}$ $\mathrm{NaHCO}_{3}, 1 \mathrm{mM} \mathrm{KH} \mathrm{PO}_{4}, 1 \mathrm{mM} \mathrm{MgCl}$ and $11 \mathrm{mM}$ glucose). The bath solution was maintained at $32^{\circ} \mathrm{C}$ and was continuously aerated with a gas mixture of $95 \%$ oxygen and $5 \%$ carbon dioxide. The $\mathrm{pH}$ of the bath solution was maintained at 7.38 to 7.42. Spent Krebs solution was exchanged with fresh solution 10 min after the preparation was mounted. The preparation was attached to a force transducer (Model 1030, UFI, Morro Bay, CA, USA) with a stainless steel wire and allowed to stabilize for $20 \mathrm{~min}$ in the bath. The phrenic nerve, connected to an electrode, was stimulated with supramaximal square wave impulses of $0.2 \mathrm{~ms}$ in duration using a stimulator (Model ML112, ADInstruments Pty Ltd, Bella Vista, NSW, Australia).

The diaphragm muscle was stretched until the maximum output tension was recorded after stimulation, followed by another $10 \mathrm{~min}$ for stabilization before the experiment began. Three consecutive single twitch tensions at $0.1 \mathrm{~Hz}$ and a 1.9-s tetanic tension of $50 \mathrm{~Hz}$ were obtained at each concentration, which were then digitized and stored on a Power Macintosh 7100 (Apple Computer Corp, Cupertino, CA, USA) using data acquisition software (MacLab, ADInstruments Pty Ltd, Bella Vista, NSW, Australia).

After baseline tensions were measured, the concentrations of rocuronium were cumulatively increased until an $80 \%$ to $90 \%$ reduction in a single twitch (ST) was reached in Krebs solution pre-treated with $0(\mathrm{n}=5), 0.1(\mathrm{n}=1), 0.25(\mathrm{n}=1), 0.5(\mathrm{n}=4)$ or $1.0(\mathrm{n}=1) \mathrm{mM}$ of clindamycin phosphate alone or in Krebs solution pre-treated with $0(\mathrm{n}=4), 0.1(\mathrm{n}=1), 0.5(\mathrm{n}=5), 1.0$ $(\mathrm{n}=5)$, or $2.0(\mathrm{n}=4) \mathrm{mM}$ of clindamycin in combination with $250 \mathrm{nM}$ neostigmine. For synergy testing, the concentrations of clindamycin were cumulatively increased until an $80 \%$ to $90 \%$ reduction in ST was reached in Krebs solution pre-treated with $0(n=5)$ or $250 \mathrm{nM}(\mathrm{n}=5)$ of neostigmine.

A period of at least $20 \mathrm{~min}$ was allowed to pass to establish a pseudo-steady state condition of each drug concentration between bath and the tissue preparation. Tension measurements were made during the pseudo-steady state and in 
the drug-free solution after completion of each experiment. Data were analyzed only if the single-twitch tension returned to greater than $90 \%$ of the baseline recording in a drug-free solution. Single-twitch tension was calculated based on the average of three consecutive single-tension measurements. The effective concentrations (EC) of rocuronium or clindamycin for ST (percent reduction of control) and TF (tetanic fade: percent increase of TF) were determined by the probit model [17] and the concentration-response curves of rocuronium and clindamycin were obtained for each pre-treatment.

To evaluate the ability of neostigmine to potentiate the NMB action of clindamycin in combination with rocuronium, the potency ratios, which were equated with the $\mathrm{EC}_{50}$ of rocuronium with clindamycin $(0.5$ and $1.0 \mathrm{mM})$ to the $\mathrm{EC}_{50}$ of rocuronium in the absence or in the presence of neostigmine, were calculated and compared to one another.

The interaction between rocuronium and clindamycin was determined using an interaction index [20] from the following equation:

$$
\text { Interaction Index }=\frac{\mathcal{C}_{R}}{C_{R}}+\frac{\mathcal{C}_{c l}}{C_{c l}}
$$

where $c_{R}$ and $c_{C l}$ are the concentrations of rocuronium and clindamycin, respectively, both of which yield an effect, E while $\mathrm{C}_{\mathrm{R}}$ and $\mathrm{C}_{\mathrm{Cl}}$ are the concentrations of each drug that produce the same effect of $E$ when given alone.

The $\mathrm{EC}_{50}$ 's of rocuronium given with clindamycin or those of rocuronium given with clindamycin in combination with neostigmine were compared using a Student's t-test with a Bonferroni's correction of the significance level. The $\mathrm{EC}_{50}$ 's of clindamycin in the absence and presence of neostigmine were compared to one another using a Student's t-test, and the $\mathrm{EC}_{50}$ 's of rocuronium with $0.5 \mathrm{mM}$ clindamycin in the absence and presence of neostigmine were also compared using a Student's t-test. Differences were considered significant when $\mathrm{P}<0.05$.

\section{Results}

Clindamycin shifted the concentration-response curves of rocuronium to the left (Fig. 1 and 2) as well as increased the potency of rocuronium for both a ST and TF, irrespective of the presence of neostigmine. Clindamycin at $1.0 \mathrm{mM}$ moved the concentration-response curve of rocuronium in the presence of neostigmine to that of rocuronium alone (Fig. 2).

To determine whether neostigmine antagonizes the neuromuscular block that is caused by combinations of clindamycin and rocuronium, the concentration-response relationships of rocuronium in combination with clindamycin or neostigmine were performed. Neostigmine at $250 \mathrm{nM}$ shifted the concentration-response curve of rocuronium to the right (Fig. 2), irrespective of the presence of clindamycin, and increased the $\mathrm{EC}_{50}$ of rocuronium with the same clindamycin concentration by approximately two-fold (Table 1). It was demonstrated that neostigmine partially antagonized the neuromuscular block that was induced by both clindamycin and rocuronium.

We examined the ability of neostigmine to potentiate the NMB action of clindamycin in combination with rocuronium by calculating the potency ratios of rocuronium. The potency ratios of rocuronium with neostigmine were higher than or similar to those observed in the absence of neostigmine (Table 1). Neostigmine failed to enhance the neuromuscular block which
A

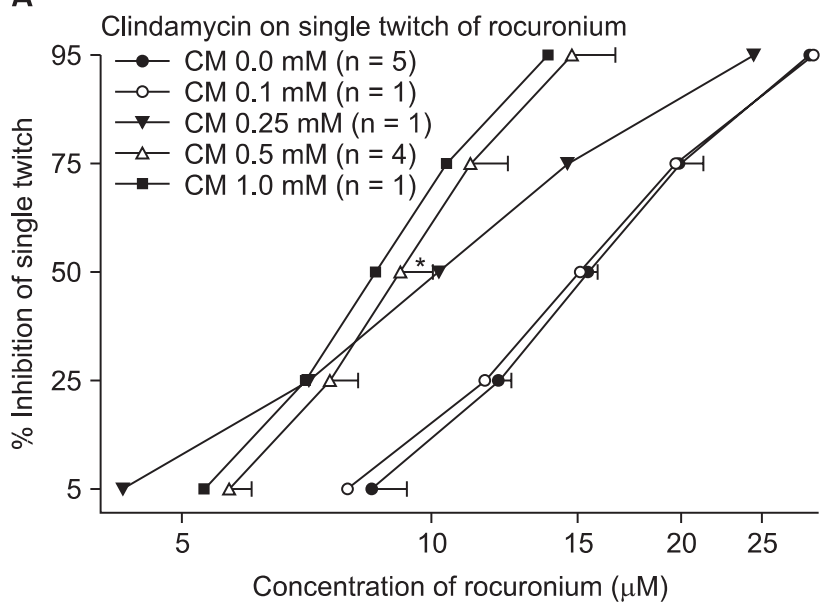

B

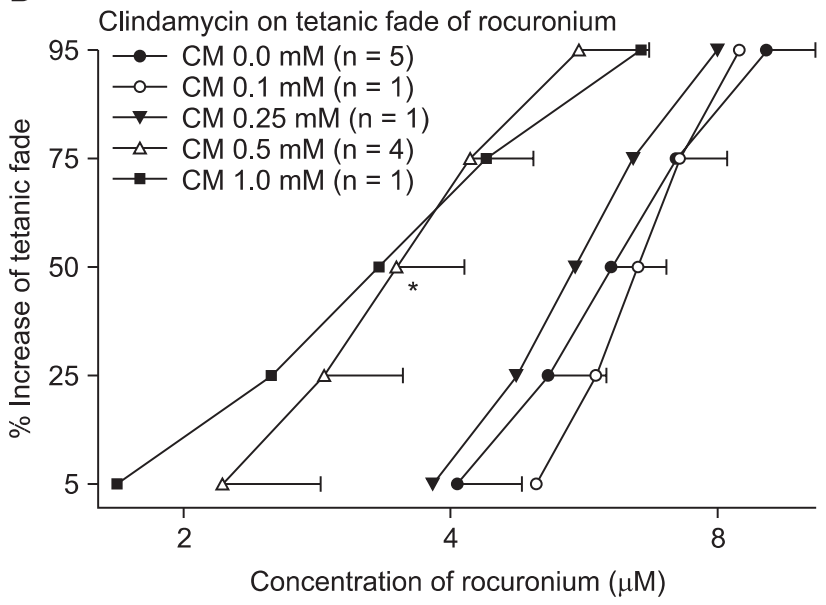

Fig. 1. Based on the cumulative concentration-effect curves for rocuronium on a ST at $0.1 \mathrm{~Hz}(\mathrm{~A})$ and $\mathrm{TF}$ at $50 \mathrm{~Hz}$ for 1.9 seconds (B), clindamycin shifted curves to the left; thus, clindamycin augments the potency of rocuronium. Twelve preparations were studied. Rocuronium concentrations are presented as means \pm SD and where a single experiment was performed $(\mathrm{n}=1$, no SD). CM: clindamycin. *Indicates $\mathrm{P}<$ $0.0009, \mathrm{EC}_{50}$ of rocuronium in $0.5 \mathrm{mM}$ clindamycin compared to no clindamycin. 
A

CM and NS (250 nM) on single twitch of rocuronium

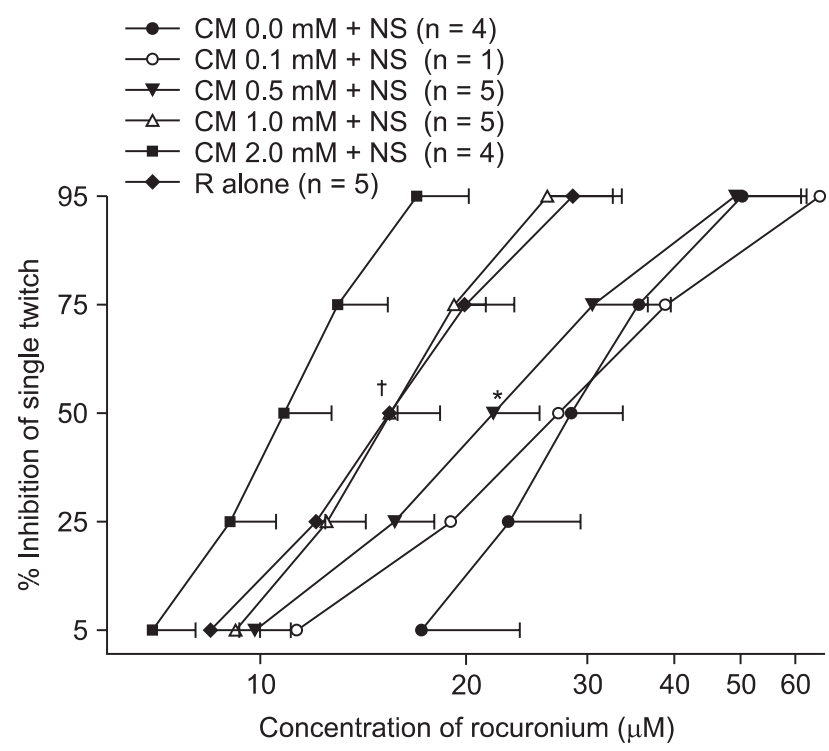

B

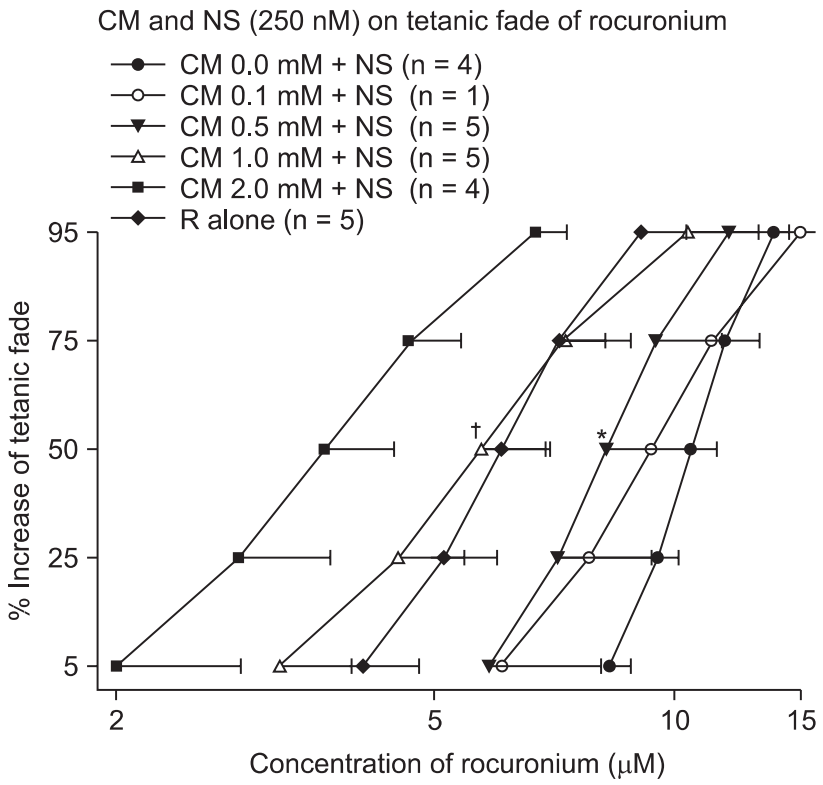

Fig. 2. Based on the cumulative concentration-effect curves for rocuronium on a ST at $0.1 \mathrm{~Hz}(\mathrm{~A})$ and $\mathrm{TF}$ at $50 \mathrm{~Hz}$ for $1.9 \mathrm{~seconds}$ (B), clindamycin shifted curves to the left; hence, clindamycin augments the potency of rocuronium in the presence of neostigmine. Clindamycin at $1.0 \mathrm{mM}$ shifted the concentration-response curve of rocuronium in the presence of neostigmine to the rocuronium alone curve. Rocuronium concentrations are presented as means \pm SD except where a single experiment was performed $(n=1$, no SD). CM: clindamycin, $\mathrm{R}$ alone: rocuronium in the absence of both clindamycin and neostigmine. *Indicates $\mathrm{P}<0.05, \mathrm{EC}_{50}$ of rocuronium with $0.5 \mathrm{mM}$ clindamycin and ${ }^{\dagger}$ Indicates $\mathrm{P}<0.005, \mathrm{EC}_{50}$ of rocuronium with $1.0 \mathrm{mM}$ clindamycin compared to no clindamycin.

Table 1. $\mathrm{EC}_{50}(\mu \mathrm{M})$ and Potency Ratios $\left(\mathrm{PR}=\mathrm{EC}_{50, \mathrm{R}+\mathrm{CM}} / \mathrm{EC}_{50, \mathrm{R}}\right)$ for Rocuronium with Different Pre-Treatments

\begin{tabular}{|c|c|c|c|c|c|}
\hline \multirow{2}{*}{ Pretreatments } & \multirow{2}{*}{$\mathrm{n}$} & \multicolumn{2}{|c|}{ ST } & \multicolumn{2}{|c|}{$\mathrm{TF}$} \\
\hline & & $\mathrm{EC}_{50}$ & PR & $\mathrm{EC}_{50}$ & PR \\
\hline $\mathrm{R}$ alone & 5 & $15.5 \pm 0.4$ & & $6.1 \pm 9$ & \\
\hline $\mathrm{R}$ in $0.5 \mathrm{mM} \mathrm{CM}$ & 4 & $9.2 \pm 0.9^{*}$ & $0.6 \pm 0.1^{\ddagger}$ & $3.5 \pm 0.7 *$ & $0.6 \pm 0.1^{\S}$ \\
\hline $\mathrm{R}$ in $1.0 \mathrm{mM} \mathrm{CM}$ & 1 & 8.6 & 0.6 & 3.3 & 0.5 \\
\hline $\mathrm{R}$ in NS & 4 & $28.4 \pm 5.3$ & & $10.5 \pm 0.8$ & \\
\hline $\mathrm{R}$ in $0.5 \mathrm{mM} \mathrm{CM}+\mathrm{NS}$ & 5 & $21.8 \pm 3.7$ & $0.8 \pm 0.1$ & $8.2 \pm 2.1$ & $0.8 \pm 0.2$ \\
\hline $\mathrm{R}$ in $1.0 \mathrm{mM} \mathrm{CM}+\mathrm{NS}$ & 5 & $15.5 \pm 2.8^{\dagger}$ & $0.5 \pm 0.1$ & $5.7 \pm 1.2^{\dagger}$ & $0.5 \pm 0.1$ \\
\hline
\end{tabular}

$\mathrm{EC}_{50}$ : effective concentrations of $50 \%$ maximal effect of rocuronium, $\mathrm{EC}_{50, \mathrm{R}+\mathrm{CM}}$ : $\mathrm{EC}_{50}$ of rocuronium with clindamycin with or without neostigmine, $\mathrm{EC}_{50, \mathrm{R}}: \mathrm{EC}_{50}$ of rocuronium alone or with neostigmine, $\mathrm{CM}$ : clindamycin, NS: $250 \mathrm{nM}$ neostigmine, R: rocuronium, ST: single twitch, TF: tetanic fade. ${ }^{*}$ Indicates $\mathrm{P}<0.0009$, versus rocuronium alone, ${ }^{\dagger}$ indicates $\mathrm{P}<0.005$, versus rocuronium with neostigmine, ${ }^{\ddagger}$ indicates $\mathrm{P}=0.02$, versus $\mathrm{PR}$ in $0.5 \mathrm{mM} \mathrm{CM}+\mathrm{NS},{ }^{\S}$ indicates $\mathrm{P}=0.05$, versus PR in $0.5 \mathrm{mM} \mathrm{CM}+\mathrm{NS}$.

was induced by both clindamycin and rocuronium.

Neostigmine shifted the concentration-response curves of clindamycin to the left and enhanced the effect of clindamycin (Fig. 3).

The interaction indices were less than 0.7 for a ST and TF with concentrations of clindamycin in excess of $0.5 \mathrm{mM}$ without neostigmine (Fig. 4). In the presence of neostigmine, the interaction indices were less than 0.7 for a ST and less than 0.9 for TF with concentrations higher than $1.0 \mathrm{mM}$ of clindamycin (Fig. 5). Because the interaction indices were less than one, the two drugs interacted synergistically. In view of the influence of neostigmine on the interaction index, neostigmine failed to boost the interaction of rocuronium and clindamycin.

\section{Discussion}

It was demonstrated that neostigmine fails to augment the degree of neuromuscular block caused by both rocuronium and clindamycin. On the contrary, neostigmine partially antagonizes the effect of rocuronium and clindamycin combinations, whereas neostigmine reduces the rocuronium potency with both clindamycin and neostigmine less than with neostig- 
mine alone. Therefore, neostigmine may be used to reverse the muscle relaxation that is induced by combinations of rocuronium and clindamycin.

A recent clinical report demonstrated that neostigmine fails to reverse both rocuronium and oral neomycin-induced neuromuscular block [16]. Edrophonium, neostigmine and pyridostigmine at sub-clinical dosages were observed to weakly

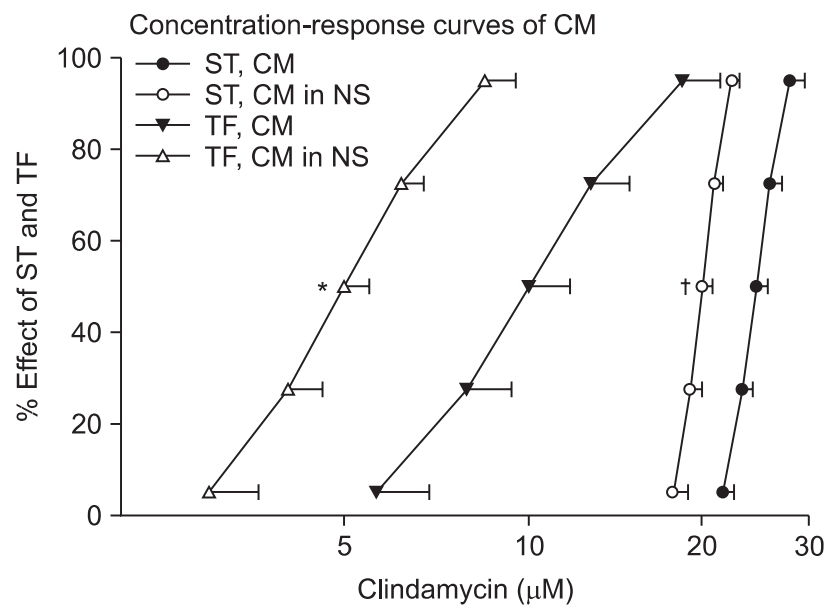

Fig. 3. Cumulative concentration-response curves of clindamycin in the absence $(n=6)$ or presence $(n=6)$ of $250 \mathrm{nM}$ neostigmine on ST $(0.1 \mathrm{~Hz})$ and TF $(50 \mathrm{~Hz})$ for 1.9 seconds. The indicated concentrations of clindamycin represent the means \pm SD of five preparations. CM, NS, ST or TF represents clindamycin, neostigmine, single twitch or tetanic fade, respectively. ${ }^{*}$ Indicates $\mathrm{P}<0.000009$ for TF, and ${ }^{\dagger}$ indicates $\mathrm{P}<0.00004$ for a ST when compared to the effect of clindamycin alone. antagonize the NMB of polymyxin B; however, at anti-curare dosages, they were observed to enhance the NMB [21]. Van Nyhuis et al. [15] observed that neostigmine augments the neuromuscular block caused by polymyxin B alone as well as in combination with pancuronium or d-tubocurarine. The antagonism by neostigmine and calcium may be incomplete at reversing the clindamycin-induced block [11] even though neostigmine augments clindamycin-induced neuromuscular block [17]. However, the results of this study indicate that neostigmine shifts the concentration-response curves of rocuronium to the right in the presence of clindamycin, which is a phenomenon that has not been observed for polymyxin $\mathrm{B}$. The reason for this discrepancy in the response to neostigmine between clindamycin and polymyxin B is not known; however, variations in the study designs, such as the use of different NMB drugs, animal species, concentrations of neostigmine and muscles studied, in addition to possible differences between the two drugs themselves, may be potential causes.

The results of this study indicate that in rat left phrenic nerve-hemidiaphragm preparations, clindamycin enhances rocuronium-induced neuromuscular block, whether or not neostigmine is present. We found that increasing the concentration of clindamycin went together with increasing rocuronium potency and the investigated concentrations of clindamycin produced little muscle relaxation.

Clindamycin causes muscle relaxation alone [17,22], enhances the activities of d-tubocurarine and pancuronium [11] in addition to prolonging the rapacuronium-induced neuromuscular block [14]. Consistent with what has been
A

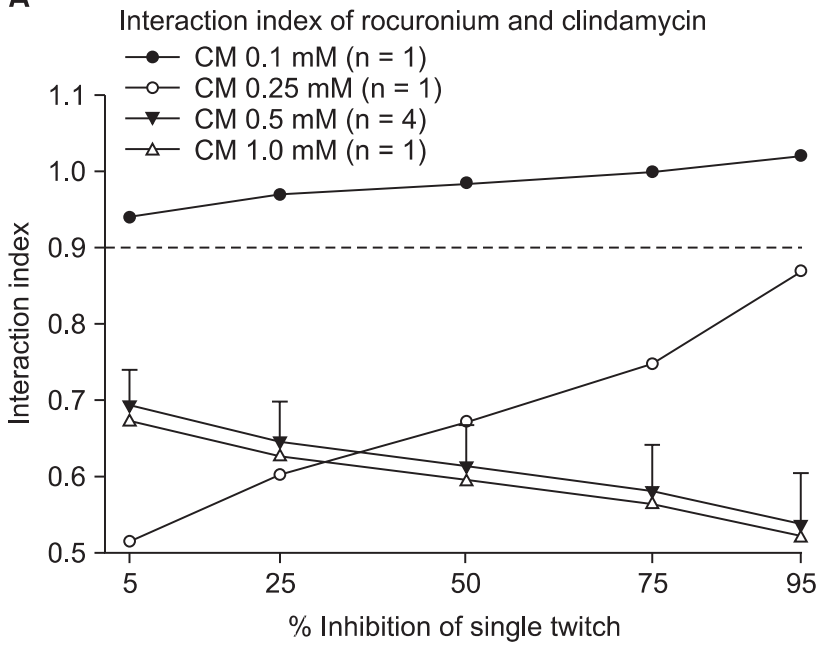

B

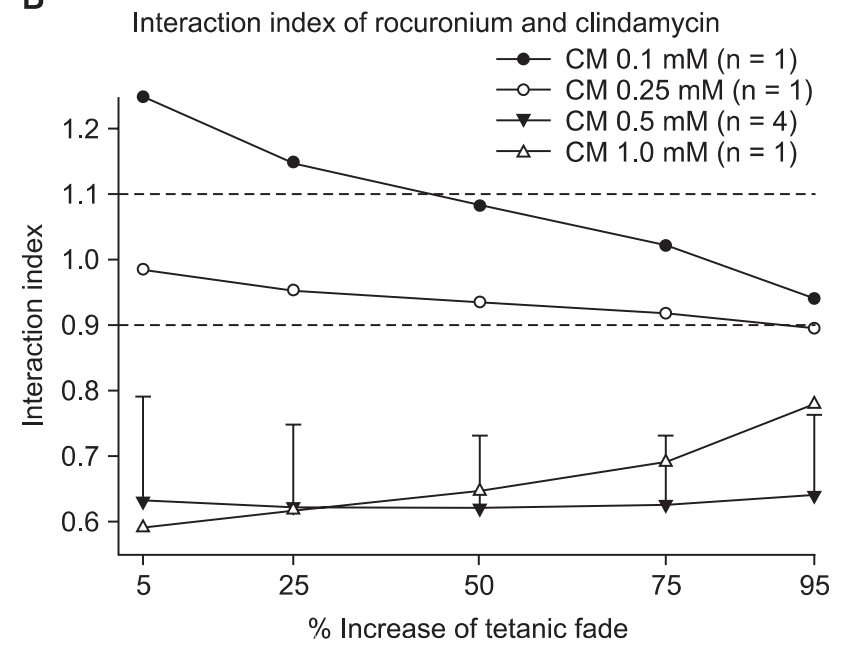

Fig. 4. Interaction indices as \% inhibition of a ST are less than 0.9 with clindamycin concentrations of $0.25,0.5$ and $1.0 \mathrm{mM}$, indicating a synergistic interaction. The interaction indices with a clindamycin concentration of $0.1 \mathrm{mM}$ lie between 0.9 and 1.1 , indicating an additive interaction (A). The interaction indices in \% increase of TF are less than 0.9 with clindamycin concentrations of 0.5 and $1.0 \mathrm{mM}$; the interaction is synergistic. The interaction indices at a clindamycin concentration of $0.25 \mathrm{mM}$ lie between 0.9 and 1.1 ; the interaction is additive (B). Data are expressed as means \pm SD except when $n=1$. CM: clindamycin. 
A

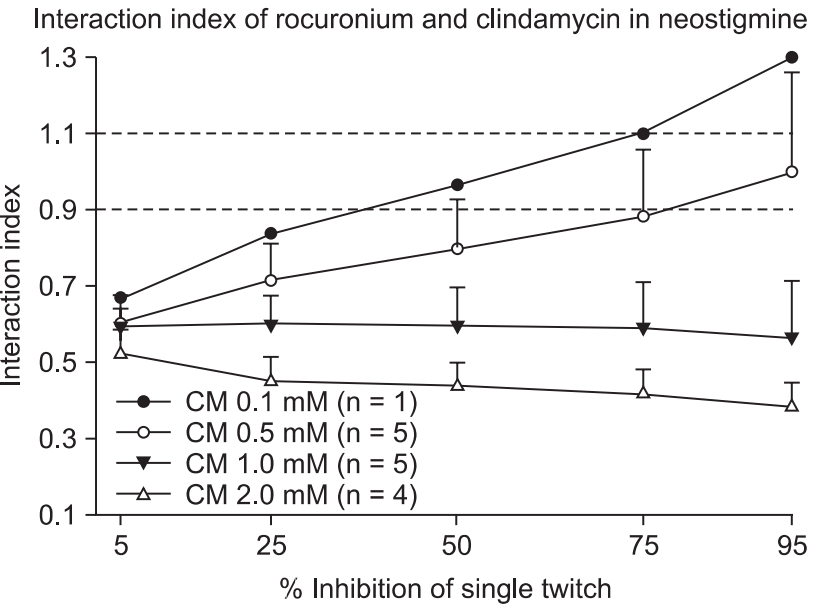

B

Interaction index of rocuronium and clindamycin in neostigmine

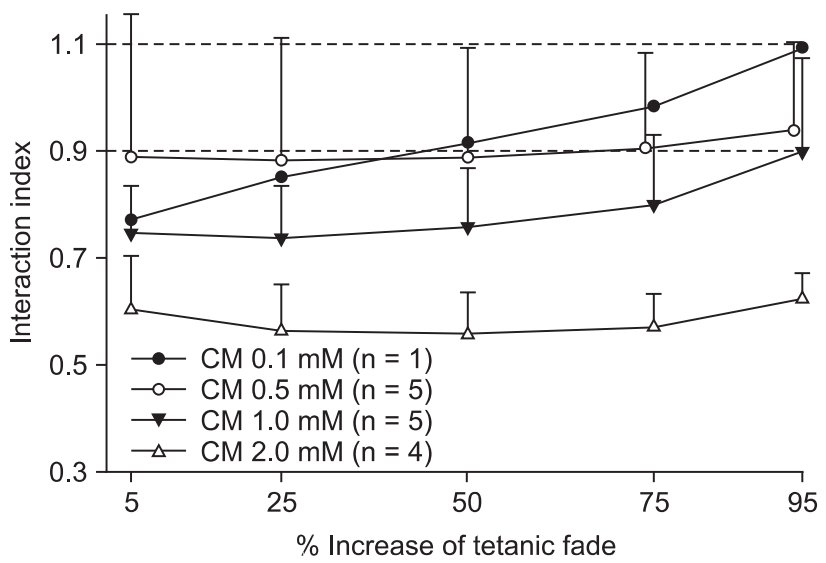

Fig. 5. The interaction indices as \% inhibition of a ST are less than 0.9 at clindamycin concentrations of $0.5,1.0,2.0$ and $5.0 \mathrm{mM}$, indicating the interaction between rocuronium and clindamycin is synergistic with a neostigmine concentration of $250 \mathrm{nM}$ (A). The interaction indices as \% increase of TF are less than 0.9 with clindamycin concentrations of 1.0 and $2.0 \mathrm{mM}$, indicating that the interaction with a neostigmine concentration of $250 \mathrm{nM}$ is synergistic. The interaction indices at a clindamycin concentration of $0.5 \mathrm{mM}$ lie between 0.7 and 1.1 , indicating an additive interaction $(B)$. Values are means \pm SD except when $n=1$. CM: clindamycin.

observed for other muscle relaxants, the results of this study indicate that clindamycin augments rocuronium-induced neuromuscular block.

Various explanations for the mechanism of clindamycininduced neuromuscular block are diverse. Some researchers have reported that clindamycin reduces end-plate current amplitude via an exclusive decrease in the quantal content of the end-plate current [7]. Some researchers have found that clindamycin affects end-plate current (or potential) decay, amplitude and quantal content; they concluded that the NMB effects of clindamycin involve both pre- and post-junctional sites $[8,9]$. Others have found that clindamycin post-junctionally produces a neuromuscular block by interacting with the open state of the acetylcholine-receptor (AChR) ion-channel complex [8]. Based on the findings of this study that augmentation of the neuromuscular block by clindamycin occurred in the presence of neostigmine, clindamycin probably blocks the open ion channels in the end-plate.

Chou and Hayball [23] have proposed that an interaction index between 0.9 and 1.1 designates an additive interaction. The interaction indices that were observed in this study indicate that clindamycin and rocuronium were synergistic in the depression of neuromuscular transmission according to Chou and Hayball's criteria.

Although it remains to be tested, several phenomena may account for the synergy of the two drugs. For example, clindamycin decreases the end-plate sensitivity to acetylcholine [24], increases acetylcholine receptor sensitivity to rocuronium, exerts a direct depressant action on muscle contractility [25], or acts with local anaesthetic activity [26]. Therefore, rocuronium may facilitate the channel blocking of clindamycin, or it may be that both rocuronium and clindamycin collaborate to decrease presynaptic acetylcholine mobilization, enhance AChR desensitization or influence the rates of binding to or unbinding from the AChR or the open channel $[27,28]$. In addition, it has been claimed that mutually nonexclusive drugs contain an element of intrinsic synergism, which may contribute to the overall synergism [29]. Because they act on the different sites in AChR ion channel complex, rocuronium and clindamycin may be mutually nonexclusive and offer some degree of intrinsic synergism.

Neostigmine slightly reduces the degree of synergistic interaction between clindamycin and rocuronium. Some complicated interactions between the three drugs may occur during their presence in the neuromuscular junction. First, acetylcholine release is decreased by clindamycin and rocuronium. Second, open-channel blocking by clindamycin and AchR occlusion by rocuronium could occur postsynaptically. Finally, it is possible that a small amount of released acetylcholine limits the increase by neostigmine in the amount of acetylcholine in neuromuscular junction and prohibits opening enough channels to enhance ion-channel block of clindamycin. Thus, it may be that neostigmine fails to increase the degree of synergistic interaction between clindamycin and rocuronium.

Clindamycin potentiates rocuronium action, but only clinically produces a muscle relaxation by itself in the setting of a clindamycin overdose (2,400 mg i.v. bolus) [22]. A dose of $900 \mathrm{mg}$ of clindamycin administered intravenously every eight hours is recommended when treating serious infections, 
and this dosage results in a serum concentration of 10 to 40 $\mu \mathrm{g} / \mathrm{ml}$ (approximately 0.03 to $0.1 \mathrm{mM}$ ) [30]. The clindamycin concentrations that were studied in this investigation are approximately five to twenty times the aforementioned clinical dose and do not cause neuromuscular block.

To diminish the number of rats used, four single $(n=1)$ experiments were conducted. Data from each single experiment were treated as a group by correcting the significance level with Bonferroni correction. We believe these single point data should be useful in interpreting the findings that were observed in this study.

It was shown that neostigmine fails to potentiate the neuromuscular block which is caused by both clindamycin and rocuronium and can partially antagonize the neuromuscular block induced by both rocuronium and clindamycin. Clinicians should be aware that clindamycin synergistically increases the degree of rocuronium-induced muscle relaxation, even in the presence of neostigmine.

\section{References}

1. Kujath P, Bouchard R, Scheele J, Esnaashari H. Current perioperative antibiotic prophylaxis. Chirurg 2006; 77: 490, 492-8.

2. Cheng EY, Nimphius N, Hennen CR. Antibiotic therapy and the anesthesiologist. J Clin Anesth 1995; 7: 425-39.

3. Naguib M, Lien CA. Pharmacology of muscle relaxants and their antagonists. In: Miller's Anesthesia. 6th ed. Edited by RD Miller: Philadelphia, Elsevier Churchill Livingstone. 2005, pp 481-572.

4. Vieira JM Jr, Castro I, Curvello-Neto A, Demarzo S, Caruso P, Pastore $\mathrm{L}$ Jr, et al. Effect of acute kidney injury on weaning from mechanical ventilation in critically ill patients. Crit Care Med 2007; 35: 184-91.

5. Howard RS, Tan SV, Z'Graggen WJ. Weakness on the intensive care unit. Pract Neurol 2008; 8: 280-95.

6. Bruckner J, Thomas KC Jr, Bikhazi GB, Foldes FF. Neuromuscular drug interactions of clinical importance. Anesth Analg 1980; 59: 678-82.

7. Prior C, Fiekers JF, Henderson F, Dempster J, Marshall IG, Parsons RL. End-plate ion channel block produced by lincosamide antibiotics and their chemical analogs. J Pharmacol Exp Ther 1990; 255: 1170-6.

8. Fiekers JF. Sites and mechanisms of antibiotic-induced neuromuscular block: A pharmacological analysis using quantal content, voltage clamped end-plate currents and single channel analysis. Acta Physiol Pharmacol Ther Latinoam 1999; 49: 242-50.

9. Singh YN, Marshall IG, Harvey AL. Pre- and postjunctional blocking effects of aminoglycoside, polymyxin, tetracycline and lincosamide antibiotics. Br J Anaesth 1982; 54: 1295-306.

10. Fogdall RP, Miller RD. Prolongation of a pancuronium-induced neuromuscular blockade by clindamycin. Anesthesiology 1974; 41: 407-8.
11. Becker LD, Miller RD. Clindamycin enhances a nondepolarizing neuromuscular blockade. Anesthesiology 1976; 45: 84-7.

12. Jedeikin R, Dolgunski E, Kaplan R, Hoffman S. Prolongation of neuromuscular blocking effect of vecuronium by antibiotics. Anaesthesia 1987; 42: 858-60.

13. de Gouw NE, Crul JF, Vandermeersch E, Mulier JP, van Egmond J, Van Aken H. Interaction of antibiotics on pipecuronium-induced neuromuscular blockade. J Clin Anesth 1993; 5: 212-5.

14. Sloan PA, Rasul M. Prolongation of rapacuronium neuromuscular blockade by clindamycin and magnesium. Anesth Analg 2002; 94: 123-4.

15. Van Nyhuis LS, Miller RD, Fogdall RP. The interaction between d-tubocurarine, pancuronium, polymyxin $\mathrm{B}$, and neostigmine on neuromuscular function. Anesth Analg 1976; 55: 224-8.

16. Hasfurther DL, Bailey PL. Failure of neuromuscular blockade reversal after rocuronium in a patient who received oral neomycin. Can J Anaesth 1996; 43: 617-20.

17. Lee SI, Lee JH, Lee SC, Lee JM, Lee JH. Calcium and neostigmine antagonize gentamicin, but augment clindamycin-induced tetanic fade in rat phrenic nerve-hemidiaphragm preparations. J Anesth 2008; 22: 385-90.

18. Loewe $\mathrm{S}$. The problem of synergism and antagonism of combined drugs. Arzneimittelforschung 1953; 3: 285-90.

19. Greco WR, Bravo G, Parsons JC. The search for synergy: A critical review from a response surface perspective. Pharmacol Rev 1995; 47:331-85.

20. Berenbaum MC. What is synergy? Pharmacol Rev 1989; 41: 93-141.

21. Lee C, Chen D, Nagel EL. Neuromuscular block by antibiotics: Polymyxin B. Anesth Analg 1977; 56: 373-7.

22. al Ahdal O, Bevan DR. Clindamycin-induced neuromuscular blockade. Can J Anaesth 1995; 42: 614-7.

23. Chou TC, Hayball M. CalcuSyn for windows: Multiple-drug doseeffect analyzer and manual. Biosoft, Cambridge Place, Cambridge, United Kingdom. 1996.

24. Rubbo JT, Gergis SD, Sokoll MD. Comparative neuromuscular effects of lincomycin and clindamycin. Anesth Analg 1977; 56: 32932

25. Fiekers JF, Marshall IG, Parsons RL. Clindamycin and lincomycin alter miniature endplate current decay. Nature 1979; 281: 680-2.

26. Jonsson M, Gurley D, Dabrowski M, Larsson O, Johnson EC, Eriksson LI. Distinct pharmacologic properties of neuromuscular blocking agents on human neuronal nicotinic acetylcholine receptors: A possible explanation for the train-of-four fade. Anesthesiology 2006; 105: 521-33.

27. Skok VI. Channel-blocking mechanism ensures specific blockade of synaptic transmission. Neuroscience 1986; 17: 1-9.

28. Peper K, Bradley RJ, Dreyer F. The acetylcholine receptor at the neuromuscular junction. Physiol Rev 1982; 62: 1271-340.

29. Chou TC. Theoretical basis, experimental design, and computerized simulation of synergism and antagonism in drug combination studies. Pharmacol Rev 2006; 58: 621-81.

30. Zambrano D. Clindamycin in the treatment of obstetric and gynecologic infections: A review. Clin Ther 1991; 13: 58-80. 